\title{
A cost-benefit analysis of prenatal screening for toxoplasmosis
}

\author{
VIC S SAHAI MSc, HEATHER ONYETT MD FRCPC MPH
}

\begin{abstract}
VS SAHAI, H ONYETT. A cost-benefit analysis of prenatal screening for toxoplasmosis. Can J Infect Dis 1996;7(4):259-263. The objective of this study was to examine critically the validity of a toxoplasma prenatal screening program, in the context of a cost-benefit analysis, as it relates to the Canadian experience. Recently, studies have suggested that early treatment of infected infants with a combination of pyrimethamine and sulfadiazine is effective in reducing the sequelae of toxoplasmosis. It was concluded that a carefully planned screening program for detecting and treating infants infected with Toxoplasma gondii during pregnancy is cost beneficial. The cost of delivering a screening and treatment program is less than half of what it would cost to provide comprehensive long term medical, educational and other social services for the estimated 1000 children born each year with congenital toxoplasmosis. Even if an incidence as low as two infected infants per 1000 pregnancies is assumed and only 400 children were affected, the screening and preventive therapy program would be justified.
\end{abstract}

Key Words: Cost-benefit analysis, Prenatal screening, Toxoplasma gondii, Toxoplasmosis

\section{Analyse coût-bénéfice du dépistage prénatal de la toxoplasmose}

RÉSUMÉ : L'objectif de cette étude était de procéder à un examen critique de la validité d'un dépistage prénatal de la toxoplasmose dans le cadre d'une analyse coût-bénéfice appliquée à l'expérience canadienne. Récemment, des études ont suggéré qu'un traitement précoce des nourrissons infectés par traitement associatif de pyriméthamine et de sulfadiazine réussit à réduire les séquelles de la toxoplasmose. On en conclut qu'un programme de dépistage sérieusement planifié pour l'identification et le traitement des nourrissons atteints d'une infection à Toxoplasma gondii durant la grossesse est avantageux sur le plan économique. Le coût d'administration d'un programme de dépistage et de traitement coûte moins de la moitié de ce qu'il en coûterait pour offrir des services médicaux, éducatifs et sociaux globaux à long terme aux 1000 enfants environ qui naissent chaque année atteints de toxoplasmose congénitale. Même si on évalue à deux nourrissons infectés par 1000 grossesses le nombre de cas et que 400 enfants seulement sont affectés, le programme de dépistage et de traitement préventif serait justifié.

$\mathrm{T}$ oxoplasmosis, a ubiquitous protozoal infection caused by an intracellular parasite, Toxoplasma gondii, is a worldwide health problem (1-3). It is generally benign in healthy people but can be serious in individuals who are immunosuppressed, especially those with AIDS $(4,5)$, transplant patients and children infected in utero (1-6). Infection of pregnant women can increase fetal morbidity and mortality. Sys- temic intrauterine infection can cause growth retardation, hepatosplenomegaly, brain calcification, hydrocephalus, seizures, mental retardation, blindness and cerebral palsy (6). The seroprevalence rate for $\mathrm{T}$ gondii among pregnant women varies between $10 \%$ and $40 \%$ in Canada $(7,8)$. In Canada, the incidence of infection with $\mathrm{T}$ gondii during pregnancy is between two and eight/1000 pregnancies (7). This means that

Sudbury and District Health Unit, Sudbury, and Hotel Dieu Hospital, Kingston, Ontario

Correspondence: Dr Heather Onyett, Associate Professor of Pediatrics, Microbiology and Immunology, Community Health and Epidemiology, Hotel Dieu Hospital, 166 Brock Street, Kingston, Ontario K7L 5G2. Telephone 613-544-3310, fax 613-549-3200

Received for publication October 16, 1995. Accepted February 14, 1996 


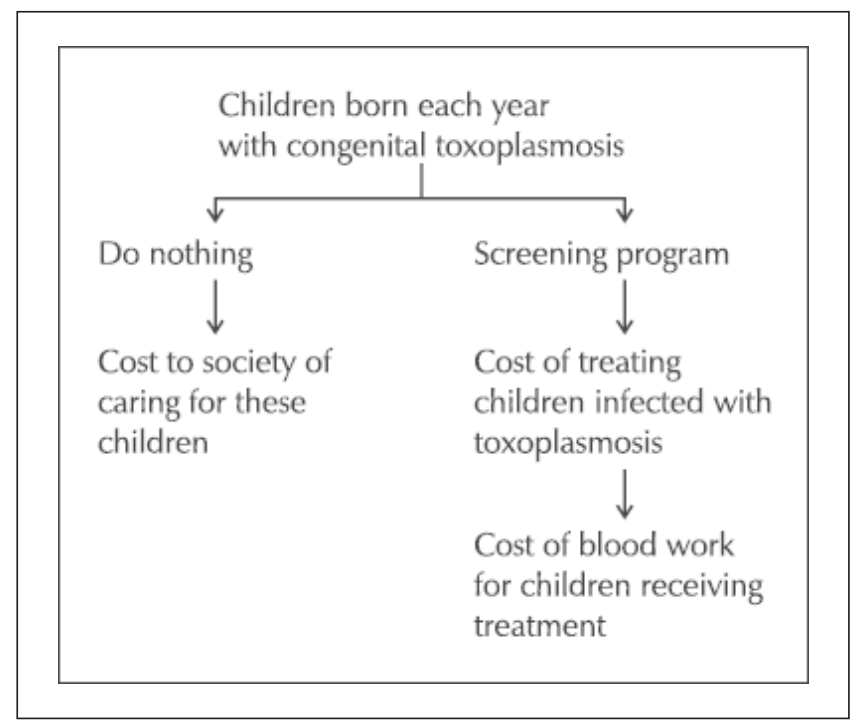

Figure 1) Flow chart of estimated costs of caring and treating children born with toxoplasmosis

one would expect 800 to 3200 maternal cases among 400,000 pregnancies in Canada each year (7). However, since the overall risk of transmission to the fetus is $50 \%(3,7)$, one would expect 400 to 1600 cases of congenital toxoplasmosis.

Approximately $25 \%$ of the infected infants are severely affected at birth, while the remaining $75 \%$ are born with unapparent infection $(7,9)$. Results of a 20 -year follow-up study of 12 congenital cases of toxoplasmosis suggests that the majority of affected infants will develop sequelae later in life (9). Recently several researchers have called for a neonatal $\mathrm{T}$ gondii screening program $(9,10)$. The rationale for such a program was based on the establishment of an efficacious treatment $(10,11)$. These researchers suggest that, if infected infants can be determined via a screening program, appropriate therapy can be instituted. The researchers suggest that the treatment has been found to be $70 \%$ effective even among the most severe cases (ie, those involving the central nervous system) $(10,11)$. It is hoped that the cost of the screening and treatment program will be less than the cost of caring for the victims of congenital toxoplasmosis that would occur in the absence of such a program (Figure 1). In this study we critically examined the validity of a toxoplasma prenatal screening program as it relates to the Canadian experience.

Until recently a serological screening program was hampered by a lack of proven therapy $(4,7,12-14)$. However, a recent multicentre clinical trial suggested that early treatment of infected infants with a combination of pyrimethamine and sulfadiazine is effective in reducing the sequelae of toxoplasmosis. The team concluded that neurological and developmental outcomes were significantly better for most of the treated children than outcomes reported for untreated children.

They suggested that infected infants should be treated as early as possible with a combination of pyrimethamine $(2 \mathrm{mg} / \mathrm{mL})$ and sulfadiazine $(100 \mathrm{mg} / \mathrm{mL})$ with supplements of folinic acid ( $5 \mathrm{mg}$ tablets) for one year. Pyrimethamine is given daily and sulfadiazine twice daily. Folinic acid supplements (two tablets or $10 \mathrm{mg}$ ) are given three times weekly (Mondays,
Wednesdays and Fridays) to counteract the myelosuppressive effects of pyrimethamine. Marrow suppression, manifested by granulocytopenia, thrombocytopenia and megaloblastic anemia, is frequent. Folinic acid selectively overcomes the marrow suppressive effects of pyrimethamine and sulfadiazine, without compromising the therapeutic efficacy against the toxoplasma tachyzoites (15). Boyer (15) suggests that the combination of the three drugs is well tolerated by most patients. However, because of the side effects associated with this therapy, complete blood and platelet counts should be obtained twice weekly. In this case marrow suppression generally is easily reversed with increased dose folinic acid or short term interruption of pyrimethamine and sulfadiazine.

\section{PATIENTS AND METHODS}

By subtracting the cost and benefits of the screening program from the lifetime costs of long term care for children with congenital toxoplasmosis, whether such a program is cost beneficial can be determined. The cost incurred with a prenatal toxoplasmosis serological screening program is the cost of the screening program itself plus the cost of treatment. This evaluation is from a societal perspective. Therefore, the benefits of such a program are the decreased cost to society of caring for the disabled children who would be born and develop in the absence of screening. All costs and benefits are based on 1994 values. This does not include the value of the improved quality of life of the child and the family when the disabilities are prevented or reduced by early diagnosis and therapy for toxoplasmosis.

Description and costs of the screening program: The screening program involves three standard serological tests for $\mathrm{T}$ gondii antibodies. They are the latex agglutination test (Tanada USA Inc, California) (cost \$10.00); a fluorescent antibody test (Microbiological Research Corp, Utah) (immunoglobulin [Ig] G, cost $\$ 15.00$ ); and a fluorescent antibody test (IgM) (Microbiological Research Corp) (cost \$15.00). Women are tested at their first prenatal visit and then again in the later stages of pregnancy. Routine blood samples (ie, to test for rubella and hepatitis B) are taken at these times. Therefore, the only costs to society are the costs of the laboratory tests. Assumptions of the screening programs are as follows:

- There are 400,000 births in Canada each year (16).

- The prevalence of toxoplasmosis seropositivity in Canada is $25 \%$ (the average seroprevalence reported by Canadian studies) $(7,8)$.

- The incidence in Canada of infection with T gondii during pregnancy is between two and eight/1000. For calculations in the present study, the median seroconversion rate of five cases/1000 pregnancies or $0.5 \%$ of all pregnancies (7) was used.

- There is a $20 \%$ false positive rate associated with the latex agglutination test.

- The fluorescent antibody tests done in a parallel series have been found to be approximately $100 \%$ sensitive and specific $(7,17)$. 
TABLE 1

Lifetime cost of special services for $1000 *$ children with congenital toxoplasmosis born in Canada each year

\begin{tabular}{|c|c|c|c|c|c|c|c|}
\hline Service required & $\begin{array}{c}\text { Utilization } \\
(\%)^{+}\end{array}$ & $\begin{array}{l}\text { Number of } \\
\text { children using } \\
\text { the service }^{+}\end{array}$ & $\begin{array}{l}\text { Cost per } \\
\text { year }(\$)\end{array}$ & $\begin{array}{c}\text { Number } \\
\text { of years } \\
\text { needed }\end{array}$ & $\begin{array}{c}\text { Total cost } \\
\text { per child }(\$)\end{array}$ & $\begin{array}{c}\text { Cost after } \\
\text { discounting } \\
(\$)^{\ddagger}\end{array}$ & $\begin{array}{c}\text { Total cost for all } \\
\text { years after } \\
\text { discounting }(\$)\end{array}$ \\
\hline Aid to totally disabled (20) & 2.4 & 24 & 13,392 & 50 & 669,600 & 1,167 & $1,401,399$ \\
\hline $\begin{array}{l}\text { Special schooling for } \\
\text { visually handicapped }^{\S}\end{array}$ & 14.2 & 142 & 22,600 & 12 & 271,200 & 12,585 & $2,144,032$ \\
\hline $\begin{array}{l}\text { Special schooling for the } \\
\text { moderately retarded }^{\S}\end{array}$ & 7.1 & 71 & 15,663 & 12 & 187,956 & 8,722 & $7,430,926$ \\
\hline $\begin{array}{l}\text { Institutional care for the } \\
\text { severely retarded }\end{array}$ & 15.0 & 150 & 66,000 & 40 & $2,640,000$ & 9,375 & $56,250,090$ \\
\hline $\begin{array}{l}\text { Yearly ophthalmological } \\
\text { follow-up care }(21)\end{array}$ & 78.0 & 780 & 200 & 60 & 12,000 & 11 & 501,093 \\
\hline Total & & & & & & 31,860 & $87,027,540$ \\
\hline
\end{tabular}

*The best estimate of the incidence rate in Canada of prenatal toxoplasma infection is five cases per 1000 pregnancies or 2000 cases among 400,000 pregnancies. However, since the overall risk of transmission to the fetus is $50 \%$, one would expect 1000 cases of congenital toxoplasmosis. ${ }^{\dagger}$ Based on follow-up studies of infected infants done by Carter and Frank (7), Koppe et al (9), and Wilson et al (16). ${ }^{*}$ The discount rate is based on 5\% per annum (17). ${ }^{\$}$ Personal communication

Calculation of the treatment cost: The treatment cost was calculated using an Excel spreadsheet program (Microsoft, Washington). The treatment is as outlined by McAuley et al (10). The treatment regimen is based on the baby's weight. A growth chart (Ross Laboratories) was used to establish the baby's weight at a given month. The costs of sulfadiazine, pyrimethamine and folinic acid were based on the cost of each drug as well as the dispensing fees (personal communication). The cost of sulfadiazine is $\$ 0.40 / \mathrm{mL}$. The cost of pyrimethamine is $\$ 0.60 / \mathrm{mL}$. The cost of folinic acid is $\$ 5.50 /$ tablet $(5 \mathrm{mg})$. The cost was calculated per child per year and then multiplied by 1000 (the estimated number of congenital toxoplasmosis cases per year in Canada). The cost also included two complete blood and platelet counts weekly per child for one year. The cost of the test and taking the blood is $\$ 15.52$ (personal communication).

The efficacy of the treatment in the most severe cases is $70 \%$ (10); therefore, one would expect that $30 \%$ of treated children will be in need of additional medical, educational and social services. This means that the cost of the treatment program would have to include $30 \%$ of the cost for special services for children with congenital toxoplasmosis as discussed below (Table 1).

Calculation of benefits: The benefit of the program is the decreased cost to society for caring for the disabled children who would be born in the absence of a screening program. The direct costs of an illness such as toxoplasmosis are medical care, special devices and special education and rehabilitation or long term care in government funded facilities. It should be noted that 'charges' for services were used as a proxy for the true cost based on actual resource utilization. Approximately $20 \%$ of children born with congenital toxoplasmosis are severely affected. The rest are born with mild subclinical infections (9).

Data presented by several authors $(7,9,17)$ were used to estimate the frequency of sequelae of children born with sub-

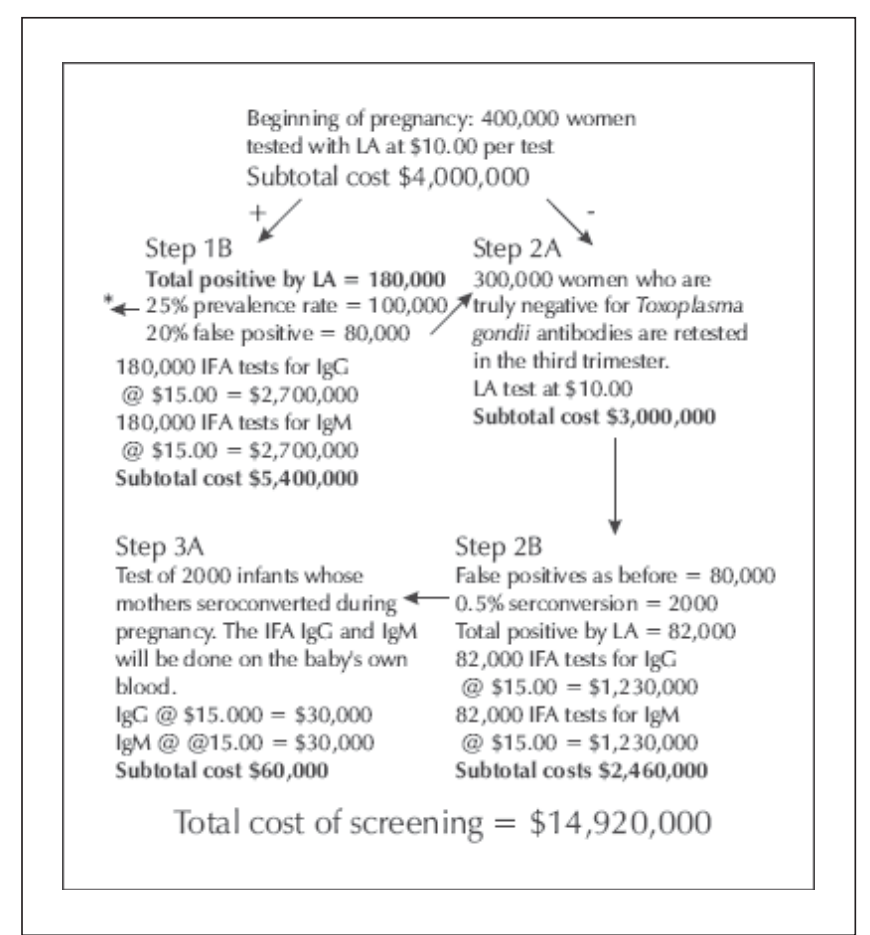

Figure 2) Flow diagram of predicted cost of a national Canadian screening program for toxoplasmosis. ${ }^{*}$ No further testing

clinical infections. Cost estimates for special care of children with congenital toxoplasmosis were based on figures provided by the appropriate agencies (Table 1). All costs were discounted at a rate of $5 \% / y e a r(18)$. The 'indirect benefits' are the value of production lost because a person is disabled or dies prematurely. In the analysis, only the 'direct costs' were considered. Also, because all costs are in 1994 values and 'charges' for services were used as proxy indicators for the 'true' cost of resource utilization, depreciation for buildings and equipment was not accounted for. 
TABLE 2

Sensitivity table for a range of incidences of congenital toxoplasmosis

\begin{tabular}{|c|c|c|c|c|c|c|c|c|c|}
\hline \multicolumn{10}{|c|}{ Incidence/1000 } \\
\hline 5.00 & 4.38 & 3.75 & 3.13 & 2.50 & 2.00 & 1.88 & 1.25 & 0.63 & 0.38 \\
\hline \multicolumn{10}{|c|}{ Number of children born each year with toxoplasmosis } \\
\hline 1000 & 875 & 750 & 625 & 500 & 400 & 375 & 250 & 125 & 75 \\
\hline \multicolumn{10}{|c|}{ Total cost of treatment program $(\$)$} \\
\hline $2,796,750$ & $2,447,156$ & $2,097,563$ & $1,747,969$ & $1,398,375$ & $1,118,700$ & $1,048,781$ & 699,188 & 349,594 & 209,756 \\
\hline \multicolumn{10}{|c|}{ Total cost of blood work (\$) } \\
\hline $1,161,080$ & $1,015,945$ & 870,810 & 725,675 & 580,540 & 464,432 & 435,405 & 290,270 & 145,135 & 87,081 \\
\hline \multicolumn{10}{|c|}{ Total cost of laboratory tests (\$) } \\
\hline $14,920,000$ & $14,912,500$ & $14,905,000$ & $14,897,500$ & $14,890,000$ & $14,884,000$ & $14,882,500$ & $14,875,000$ & $14,867,500$ & $14,864,500$ \\
\hline
\end{tabular}

Total cost of treatment, blood work and screening (\$)

$18,877,830 \quad 18,375,601 \quad 17,873,373 \quad 17,371,144 \quad 16,868,915 \quad 16,467,132 \quad 16,366,686 \quad 15,864,458 \quad 15,362,229 \quad 15,161,337$

$\mathbf{3 0} \%$ of cost accounting for the efficacy of drugs (\$)

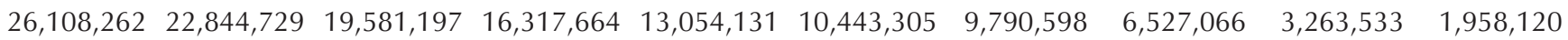

Total cost of treatment, blood work and screening including $\mathbf{3 0} \%$ accounting for drug efficacy (\$)

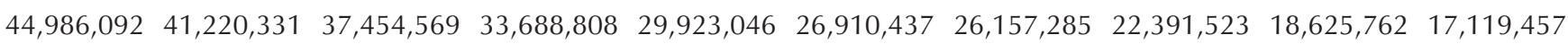

Cost of providing care to children born with toxoplasmosis in the absence of a screening

$87,027,540 \quad 76,149,098 \quad 65,270,655 \quad 54,392,213 \quad 43,513,770 \quad 34,811,016 \quad 32,635,328 \quad 21,756,885 \quad 10,878,443 \quad 6,527,066$

Screening and treatment cost as a percentage of the cost of caring for children in the abscence of the screening program
$52 \%$
$54 \%$
$57 \%$
$62 \%$
$69 \%$
$77 \%$
$80 \%$
$103 \%$
$171 \%$
$262 \%$

\section{RESULTS}

Table 1 suggests that the direct cost to the health care system of congenital toxoplasmosis is staggering. Even after discounting, the cost of caring for children born with toxoplasma infections was estimated to be $\$ 87,027,540$. Again, this figure includes only the direct cost. It does not include the indirect cost to society, which would be equally as impressive.

Each step and cost of a national Canadian prenatal screening program for toxoplasmosis is outlined in Figure 2 . At the beginning of pregnancy all women will be tested. The total cost for this was calculated to be $\$ 4,000,000$. Since there is a $20 \%$ false positive rate associated with the latex agglutination test, all women who are positive therefore have to be tested via an immunofluorescent antibody (IFA) IgG and IFA IgM test to determine whether they are truly positive. Therefore, for the 400,000 women tested, 180,000 (the $25 \%$ of women who were previously infected before pregnancy and the $20 \%$ who are false positive) have to be confirmed. This would cost an estimated $\$ 5,400,000$. During the third trimester of pregnancy the 300,000 women who are negative for the toxoplasmosis antibodies will have to be retested in order to identify those who seroconverted during pregnancy (Step 2A). This would cost an estimated $\$ 3,000,000$. Also, the women who were false positive before and those women who seroconverted have to be confirmed (Step 2B) at an estimated cost of $\$ 2,460,000$. Since only $50 \%$ of the infected mothers pass on the infection to the baby, the infant's own blood has to be tested to determine whether infection occurred in utero. The cost would be $\$ 60,000$. In total the estimated cost of the screening program would be $\$ 14,920,000$.

The cost of treating the children was estimated to be $\$ 2,796,750$ based on the following calculations. The cost of sulfadiazine per child, on average, would be $\$ 693 /$ year; the cost of pyrimethamine per child would be $\$ 519.75$; and the cost of folinic acid supplements would be $\$ 1,584$. Therefore, the total cost of treatment per child for one year would be $\$ 2,796.75$. By multiplying this amount by the total number of infected children expected each year (1000) one can estimate that the cost of the treatment program per year would be $\$ 2,796,750$. The cost for complete blood work for one child per year would be $\$ 1,161.08$; the cost for the 1000 children infected would be $\$ 1,161,080$. Therefore, in total the cost of the screening and a one-year treatment program would be $\$ 18,877,830$.

As stated above, the treatment is only $70 \%$ efficacious in severe cases involving the central nervous system. Therefore, $30 \%$ of the cost to treat children with congenital toxoplasmosis ( $30 \%$ of $\$ 87,027,540$ or $\$ 26,108,262$ ) has to be added to the cost of the one-year preventative therapy program. The total cost of the treatment program, after the treatment's efficacy is accounted for, is $\$ 44,986,092$ (Figure 2).

The cost of the screening and one-year preventative therapy program for infants infected in utero is approximately half 
of the cost of long term care for the children born each year with toxoplasma infections.

A sensitivity table (Table 2) gives, for a range of incidences, the cost of the screening and infant treatment program relative to the cost of caring for the infected infants born each year in the absence of such a program.

\section{LIMITATIONS}

One of the limitations of this study is that only 'direct' costs were considered. Such indirect costs as the value of lost production due to disabilities or premature death were not included in the analysis. It should be noted that the indirect cost would affect the cost of caring for the infected infants in the absence of the screening program. Also, not included in the analysis is the pain and suffering incurred by the children born with toxoplasma infections and their family because this is very difficult to quantify.

\section{DISCUSSION}

The Canadian Task Force on the Periodic Health Examination (19) in 1979 recommended that all pregnant women be serologically tested for antibodies to $\mathrm{T}$ gondii. Ideally, all pregnant women would be tested early in pregnancy and seronegative women would be tested at least once at the end of their pregnancy. In an optimal protocol an infected mother and child can be detected and appropriate therapy can be instituted. In 1979 when this recommendation was made such a screening program was hampered by the unavailability of universally acceptable treatment for pregnant women with toxoplasmosis.

However, today a carefully planned screening program for detecting and treating infants who were infected with T gondii during pregnancy is cost beneficial. Recent studies have suggested that early treatment of infected infants with pyrimethamine and sulfadiazine is effective in reducing the adverse outcomes associated with this disease. The cost of delivering a screening and treatment program is less than half of what it would cost to provide comprehensive long term medical and social care for the 1000 children born each year in Canada with congenital toxoplasmosis.

If we assume that the incidence is as low as two/1000 (400 infants are affected each year), the estimated cost of the screening and one-year treatment program is $\$ 16,467,132$. The total cost of the prevention program after the treatment efficacy is accounted for will be $\$ 26,910,437$ (Table 2). We estimated that the cost of caring for the 400 infected infants born each year would be $\$ 34,811,016$. Therefore, even if it is assumed that only 400 infants are infected each year, the cost of the screening and one-year preventative therapy is still $23 \%$ less than the cost of caring for these children born each year in the absence of a screening program. In fact the screening and treatment cost would be justified for any incidence greater than 1.25/1,000 pregnancies (or 250 infants affected each year) (Table 2).

\section{CONCLUSIONS}

A screening program would increase the proportion of infected infants who are detected and treated. In the past a preventive serological screening program, however, was hampered by the lack of a proven treatment. Recently, the efficacy of drugs to treat postnatal toxoplasmosis has been properly established and has been shown to be good. Therefore, we conclude that it is likely that the health care system in Canada could deliver a screening and treatment program for toxoplasmosis in a cost efficient manner. Even if one assumes that only 400 children are born each year with congenital toxoplasmosis a screening and preventive therapy program is still cost-beneficial.

\section{REFERENCES}

1. Frenkel JK. Toxoplasma in and around us. Bioscience 1973;23:343-51.

2. Williams H. Toxoplasma in the perinatal period. Postgrad Med J 1977;53:614-7.

3. Al-Meshari A, Chowdhury MN, Chattopadhyay SK, DeSilva SK. Screening for toxoplasmosis in pregnancy. Int J Gynaecol Obstet 1989;29:39-44.

4. Koskiniemi M, Lappalainen M, Hedman K, et al. Toxoplasmosis needs evaluation - an overview and proposal. Am J Dis Child 1989;143:724.

5. McCabe R, Remington JS. Toxoplasmosis the time has come. N Engl J Med 1988;318:313-5.

6. Rosenfeld JA. Maternal and congenital toxoplasmosis: is prevention possible. Postgrad Med 1988;84:187-90.

7. Carter AO, Frank J. Congenital toxoplasmosis - epidemiologic features and control. Can Med Assoc J 1979;121:618-28.

8. Sahai V, Onyett H, Steele R, Notenboon R, Subramanyan T. A Kingston pilot study of toxoplasmosis among pregnant women: prevalence and risk factors. 58th Conjoint Meeting on Infectious Diseases. Halifax, November 25-29, 1990:I-5.

9. Koppe JG, Loewer-Sieger DH, DeRoever-Bonnet H. Results of 20 year follow-up of congenital toxoplasmosis. Lancet 1986;i:254-6.

10. McAuley J, Boyer KM, Patel D, et al. Early and longitudinal evaluations of treated infants and children and untreated historical patients with congenital toxoplasmosis: the Chicago collaborative treatment trial. Clin Infect Dis 1994;18:38-72.

11. Roizen N, Swisher CN, Stein M, et al. Neurologic and developmental outcome in treated congenital toxoplasmosis. Pediatrics 1995;95:11-20.

12. McCabe RE, Oster S. Current recommendations and future prospects in the treatment of toxoplasmosis. Pract Ther 1989;38:973-86.

13. Jeannell D, Costagliola D, Niel G, Hubert B, Danis M. What is known about the prevention of congenital toxoplasmosis. Lancet 1990;336:359-60.

14. Desmonts G, Forester F, Daffos F, Capella-Pavlovsky M, Thuilliez P, Chartier M. Prenatal diagnosis of congenital toxoplasmosis. Lancet 1985;i:500-4.

15. Boyer K. Diagnosis and Treatment of Congenital Toxoplasmosis. Adv Ped Infect Dis, Vol 11. St Louis: Mosby Year Book Inc, 1996.

16. Canadian Institute of Child Health. The Health of Canada's Children: A CICH Profile, 2nd edn. Ottawa: Health Canada, 1994:15.

17. Wilson C, Remington J, Stagno S, Reynolds D. Development of adverse sequelae in children born with subclinical congenital toxoplasma infection. Pediatrics 1980;66:767-74.

18. Drummond MF. Economic Appraisal of Health Technology in the European Community. Oxford: Oxford University Press, 1987.

19. The Canadian Task Force on the Periodic Health Examination.Task Force Report. Can Med Assoc J 1979;121:1193-254.

20. Social Assistance and Pension Rate Table. Toronto: Statistics and Analysis Unit Social Assistance Program Branch, 1995.

21. OHIP Billing Schedule 1994. Toronto: Ministry of Health, 1992. 


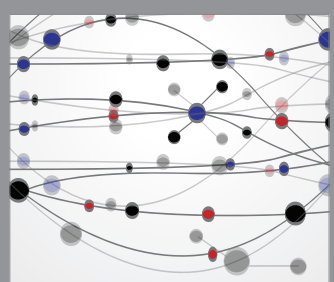

The Scientific World Journal
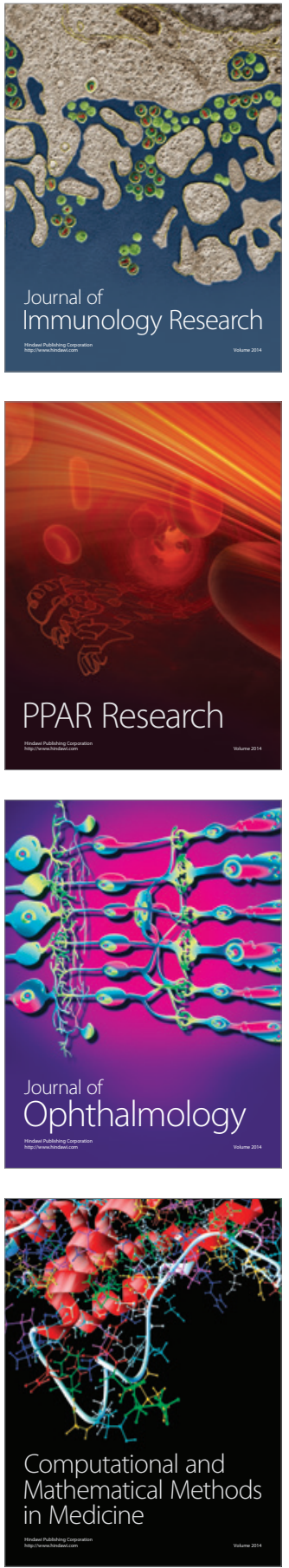

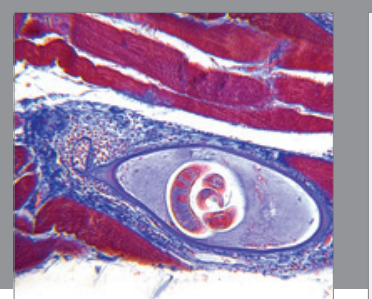

Gastroenterology Research and Practice

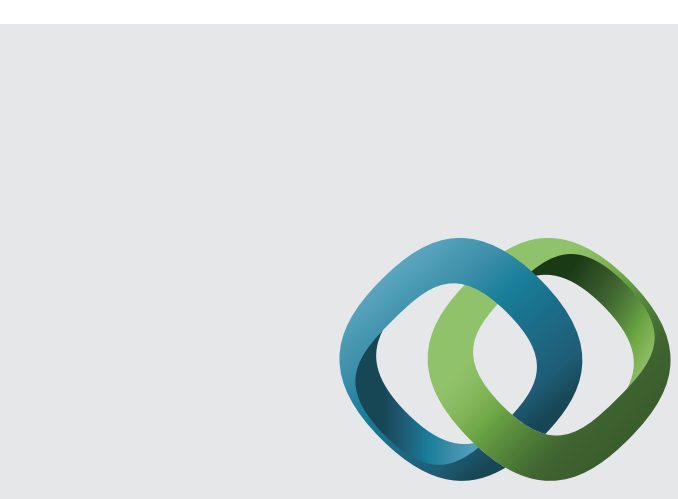

\section{Hindawi}

Submit your manuscripts at

http://www.hindawi.com
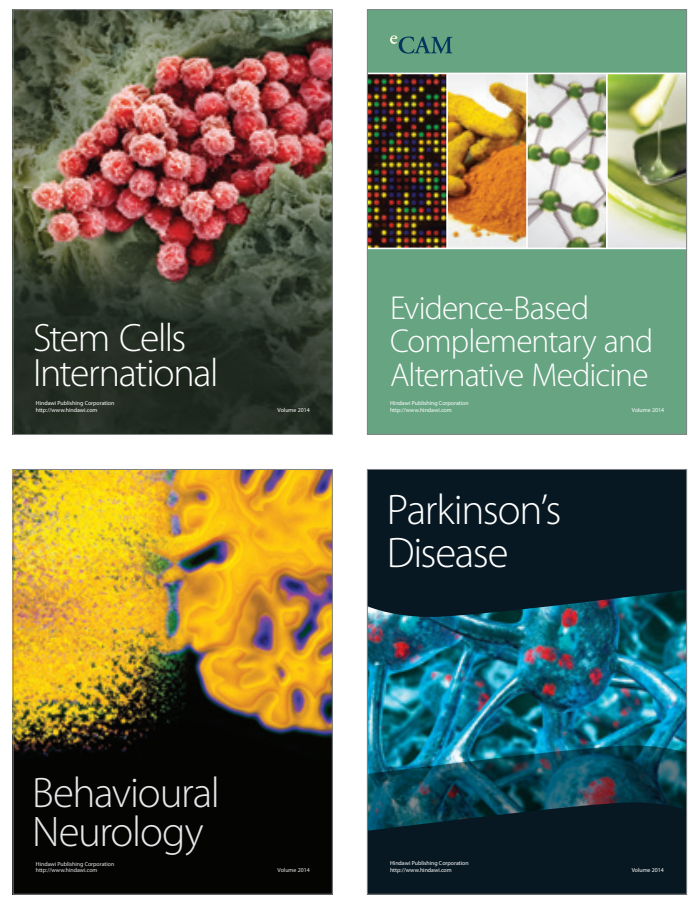
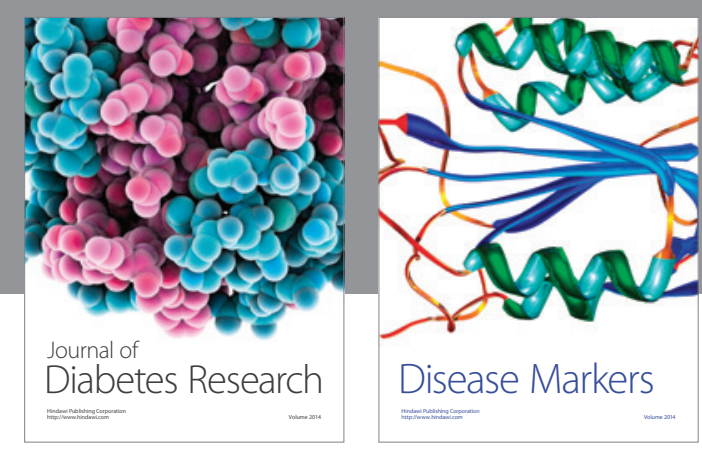

Disease Markers
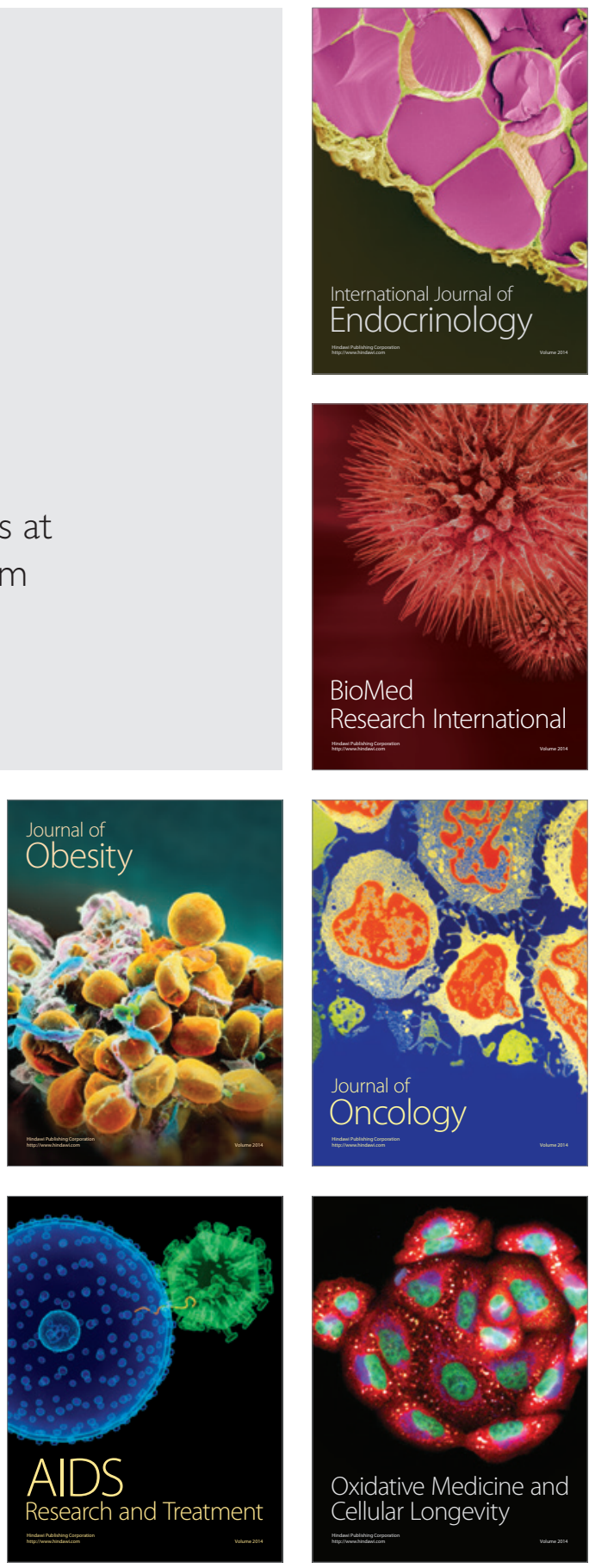